\title{
High-dose cyclophosphamide followed by autologous peripheral blood progenitor cell transplantation improves the salvage treatment for persistent or sensitive relapsed malignant lymphoma
}

R.C. Baldissera ${ }^{1}$,

J.F.P. Aranha², G.B. Oliveira²,

A.C. Vigorito ${ }^{2}$, K.A.B. Eid²,

E.C.M. Miranda ${ }^{2}$

and C.A. De Souza²

\author{
1Faculdade de Medicina de Marília, Marília, SP, Brasil \\ ¿Unidade de Transplante de Medula Ó ssea, \\ Universidade Estadual de Campinas, Campinas, SP, Brasil
}

\section{Correspondence \\ C.A. De Souza \\ Centro de Hematologia e \\ Hemoterapia \\ Unidade de Transplante de \\ Medula Ó ssea, UNICAM P \\ Caixa Postal 6198 \\ 13081-970 Campinas, SP \\ Brasil \\ Fax: + 55-19-3788-8600 \\ E-mail: carmino@ unicamp.br \\ Publication supported by FAPESP}

Received January 26, 2001 Accepted October 10, 2001

\section{Abstract}

Trials have demonstrated that high-dose escalation followed by autologous transplantation can promote better long-term survival as salvage treatment in malignant lymphomas. The aim of the present nonrandomized clinical trial was to demonstrate the role of high-dose cyclophosphamide (HDCY) in reducing tumor burden and also to determine the effectiveness of HDCY followed by etoposide (VP-16) and methotrexate (MTX) in Hodgkin's disease plus high-dose therapy with peripheral blood progenitor cell (PBPC) transplantation as salvage treatment. From 1998 to 2000, 33 patients with a median age of 33 years (13-65) affected by aggressive non-Hodgkin's lymphoma (NHL) (60.6\%) or persistent or relapsed Hodgkin's disease (39.4\%) were enrolled and treated using high dose escalation (HDCY + HDVP-16 plus HDMTX in Hodgkin's disease) followed by autologous PBPC transplantation. On an "intention to treat" basis, 33 patients with malignant lymphomas were evaluated. The overall median follow-up was 400 days (40-1233). Thirty-one patients underwent autografting and received a median of $6.19 \times 10^{6} / \mathrm{kg}(1.07-29.3)$ $\mathrm{CD}^{+}{ }^{+}$cells. Patients who were chemosensitive to HDCY $(\mathrm{N}=22)$ and patients who were chemoresistant $(\mathrm{N}=11)$ presented an overall survival of 96 and $15 \%$, respectively $(\mathrm{P}<0.0001)$. Overall survival was $92 \%$ for chemosensitive patients and $0 \%$ for patients who were still chemoresistant before transplantation $(\mathrm{P}<0.0001)$. Toxicity-related mortality was $12 \%$ (four patients), related to HDCY in two cases and to transplant in the other two. HDCY + HDVP-16 plus HDMTX in only Hodgkin's disease followed by autologous PBPC proved to be effective and safe as salvage treatment for chemosensitive patients affected by aggressive NHL and Hodgkin's disease, with acceptable mortality rates related to sequential treatment.
Key words

- Malignant lymphomas

- High-dose

cyclophosphamide

- Autologous peripheral blood progenitor cell transplantation

- Salvage therapy 


\section{Introduction}

The non-Hodgkin's lymphomas (NHL) are chemosensitive malignancies. However, responses to initial chemotherapy and radiation therapy are effective in only a minority of patients(1). Anthracycline-containing regimens, specifically the classic CHOP, have been used as the main therapy for intermediate- and high-grade NHL since 1970 (2,3). Approximately 70 to $80 \%$ of the patients with aggressive NHL respond to $\mathrm{CHOP}$, but many of them will relapse and only $40 \%$ can be cured. Regimens defined as third generation have failed to demonstrate a significant advantage over CHOP in this category of patients (4-6). The management of refractory or relapsing NHL is usually disappointing and the long-term survival rate is less than $10 \%$ with conventional salvage therapy $(7,8)$. Results indicate that, in these patients, high-dose therapy (HDT) would provide durable remission in $50 \%$ of the patients with recurrences of chemosensitive disease, with early transplant-related mortality of about $5 \%$ (9). Concerning Hodgkin's disease, the current combination of chemotherapy and radiotherapy programs results in cure in about 60 to $85 \%$ of patients. Among patients who fail to respond or relapse, the efficacy of second-line therapy is directly related to the duration of the initial response rate (10). A large number of phase II trials have evaluated the role of autologous transplantation for patients with relapsed and refractory Hodgkin's disease. These reports show that long-term disease-free survival can be achieved following autografting, and can be performed with low mortality (9). The best results of autografting are achieved when initial remission duration is longer than one year (11). Peripheral blood progenitor cell (PBPC) autografting may be feasible and progenitor cells can be obtained using mobilization after chemotherapy-induced neutropenia (12). High-dose cyclophosphamide (HDCY) followed by growth factors is the most widely used chemotherapy for obtaining PBPC (13-15). In the present study we enrolled patients pretreated for aggressive NHL and Hodgkin's disease with relapsed or refractory disease. Our aims were to evaluate the role of HDCY in reducing tumor burden, promoting efficient mobilization of $\mathrm{CD}^{+}{ }^{+}$cells. We also determined the effectiveness of HDCY followed by HDT with PBPC autografting as salvage treatment for these patients.

\section{Patients and Methods}

\section{Eligibility criteria and definitions}

Between July 1998 and September 2000, 33 patients with a median age of 33 years (range 13-65) with diffuse intermediate- and high-grade NHL as defined by the "Working Formulation" (WF) (16) and Hodgkin's disease submitted to HDT and autografting with PBPC as salvage therapy entered the study. Eligibility criteria included: 1) diagnosis of intermediate- or high-grade NHL as defined in the WF or Hodgkin's disease; 2) NHL or Hodgkin's disease patients who had failed to achieve a complete remission, NHL patients who had sensitive or resistant relapse, Hodgkin's disease patients who had an early relapse (less than 18 months), and patients primarily refractory to multi-agent chemotherapy; 3) normal cardiac, renal, pulmonary and hepatic function. Disease status was defined before HDCY and HDT as follows: partial response was considered for patients who achieved a greater than $50 \%$ reduction in tumor mass after conventional treatment; non-response, for patients with less than $50 \%$ reduction or with progressive disease; sensitive-relapse, for patients who relapsed after a complete remission and still showed a partial response to conventional salvage therapy; resistant-relapsed, for patients who relapsed with no response or less than a $50 \%$ response to conventional chemotherapy. 


\section{Patient characteristics}

Thirty-three patients participated in the study. Twenty $(60.6 \%)$ with a diagnosis of NHL and $13(39.4 \%)$ with a diagnosis of Hodgkin's disease. Twenty patients with NHL were classified according to WF. Histological classification according to WF was: group $\mathrm{D}$, one patient $(3.0 \%)$; group $\mathrm{E}$, one patient (3.0\%); group $\mathrm{F}$, two patients $(6.1 \%)$; group $\mathrm{G}, 14$ patients (42.4\%); group $\mathrm{H}$, one patient $(3.0 \%)$, and group $\mathrm{K}$, one patient (3.0\%). We studied 13 patients (39.4\%) with Hodgkin's disease. Patients were evaluated by conventional chest X-ray, chest and abdominal tomography and/or ultrasound scan and bilateral iliac crest biopsies. Patients were staged at diagnosis according to the Ann Arbor System. One patient (3.0\%) was stage I; 11 (33.3\%), stage II; 6(18.2\%), stage III, and 15 patients (45.5\%), stage IV. Twenty-one (63.6\%) patients had presented B symptoms ( $\geq 10 \%$ weight loss and/or fever and/or sweat). All patients had received extensive conventional treatment prior to HDCY, including CHOP (17), F-MACHOP (17), VACOP-B (17), and DHAP (8). Patients with Hodgkin's disease received MOPP-ABVD and MOPP (10). Patients were pretreated with a median of one conventional chemotherapy line before HDCY (13); 21 patients with one line, nine patients with two lines, and three patients with three lines. Twelve patients had achieved a partial response after first- or second-line therapy, and were considered chemosensitive. Eleven patients had a chemosensitive relapse. Ten patients were non-responders to conventional treatment, with progressive disease. In conclusion, 23 patients $(69.7 \%)$ had chemosensitive disease and $10(30.3 \%)$, chemoresistant disease. Ten patients (30.3\%) had bone marrow involvement and five patients (15.2\%), one or more other extra-nodal localization. Patient characteristics are reported in Table 1. Complete restaging, including two posterior iliac crest biopsies and chest and abdo- men computed tomography, were performed after HDCY. A gallium scan was performed when tomography was inconclusive. Clinical, laboratory and image controls were performed every three months during the first two years following PBPC rescue, and every year over successive years.

\section{Mobilization and peripheral blood progenitor cell collection}

A central venous catheter (Hickman, 13.5 fr, double line) was inserted in all cases for chemotherapy and PBPC collection. CY was administered to $31 / 33(91.6 \%)$ patients at the dose of $7 \mathrm{~g} / \mathrm{m}^{2}$. Two patients received $\mathrm{CY}$ at the dose of $4 \mathrm{~g} / \mathrm{m}^{2}$ due to borderline cardiac function (ejection function at the lower limit). The $C Y$ dose of $4 \mathrm{~g} / \mathrm{m}^{2}$ was divided into four infusions and the dose of

Table 1. Characteristics of patients on high-dose cyclophosphamide.

\begin{tabular}{|c|c|c|c|}
\hline Characteristics & $\mathrm{N}$ & & $\%$ \\
\hline Age - median/years (range) & & $33(13-65)$ & \\
\hline \multicolumn{4}{|l|}{ Sex } \\
\hline Male & 17 & & 51.5 \\
\hline Female & 16 & & 48.5 \\
\hline \multicolumn{4}{|l|}{ Diagnosis } \\
\hline Non-Hodgkin's lymphoma & 20 & & 60.6 \\
\hline Hodgkin's disease & 13 & & 39.4 \\
\hline \multicolumn{4}{|l|}{ Stage } \\
\hline$|-| \mid$ & 12 & & 36.3 \\
\hline III & 6 & & 18.2 \\
\hline IV & 15 & & 45.5 \\
\hline B symptoms & 21 & & 63.6 \\
\hline Extra-nodal localization & 5 & & 15.2 \\
\hline Bone marrow involved & 10 & & 30.3 \\
\hline Lactate dehydrogenase level - median (range) & & $348(125-1112)$ & \\
\hline \multicolumn{4}{|l|}{ Previous chemotherapy lines } \\
\hline 1 & 21 & & 64 \\
\hline 2 & 9 & & 27 \\
\hline$>2$ & 3 & & 9 \\
\hline \multicolumn{4}{|l|}{ Disease status } \\
\hline Partial remission & 12 & & 36.4 \\
\hline Sensitive with relapse & 11 & & 33.3 \\
\hline Disease progression & 10 & & 30.3 \\
\hline Overall survival - median/days (range) & & $400(40-1233)$ & \\
\hline Disease-free survival - median/days (range) & & $373(35-1224)$ & \\
\hline Status presens (alive/dead) & $24 / 9$ & & $72.7 / 27$ \\
\hline
\end{tabular}


$7 \mathrm{~g} / \mathrm{m}^{2}$ was divided into five infusions. All patients received hyperhydration with saline solution $+30 \mathrm{mEq} / 1 \mathrm{KCl}+30 \mathrm{mEq} / 1 \mathrm{NaHCO}_{3}$ $\left(3000 \mathrm{ml} \mathrm{m}^{2} 24 \mathrm{~h}^{-1}\right)$ starting at least $12 \mathrm{~h}$ before CY, and uromitexan, 1:1 in proportion to CY. Intravenous furosemide $(20 \mathrm{mg})$ before the first dose of CY, $250 \mathrm{mg}$ acetazolamide po every $6 \mathrm{~h}$, starting $4 \mathrm{~h}$ before $\mathrm{CY}$, and $8 \mathrm{mg}$ ondansetron were administered before $\mathrm{CY}$ and every $8 \mathrm{~h}$, as required. Diuresis and urinary $\mathrm{pH}$ were determined every $2 \mathrm{~h}$. From day +1 , after HDCY, $5 \mu \mathrm{g}$ $\mathrm{kg}^{-1}$ day $^{-1} \mathrm{G}-\mathrm{CSF}$ was administered $s c$ until white blood cells increased to $>1.0 \times 10^{9} / 1$ in order to collect more than $5 \times 10^{6} \mathrm{CD} 34^{+}$ cells/kg body weight. Growth factors were stopped after the last leukapheresis. The median leukapheresis was 3 (range 1-8). After HDCY, all patients received $2 \mathrm{~g} / \mathrm{m}^{2}$ etoposide (VP-16). All patients with Hodgkin's disease also received $8 \mathrm{~g} / \mathrm{m}^{2}$ methotrexate between HDCY and VP-16, according to the Institutional Protocol, before autologous bone marrow transplant (ABMT). $\mathrm{CD} 34^{+}$cells were counted by flow cytometry and the apheresis product was cryopreserved as described elsewhere (13).

\section{High-dose therapy and autologous bone marrow transplantation}

The median time between HDCY and HDT followed by autografting was 108 days (40-261). Patients with Hodgkin's disease received $8 \mathrm{~g} / \mathrm{m}^{2}$ methotrexate between HDCY and VP-16. Thirty-one patients underwent HDT. These patients received a 6-day period of chemotherapy according to the BEAM protocol (18). PBPC were re-infused on the day following HDT, nominally day 0 of the transplant procedure. Patients were randomized to receive growth factors on day +1 or +5 after autografting (19).

\section{Supportive care}

Patients were treated in single rooms with- out laminar air flow during the procedures for obtaining PBPC. Transplanted patients were allowed to recover in single rooms with a laminar air flow. All patients received supportive care as described by the Institutional Protocol for ABMT. Platelet transfusions from individual donors were given when platelet counts dropped below $20 \mathrm{x}$ $10^{9} / 1$. Leukocyte-free erythrocyte concentrates were administered when hemoglobin dropped below $8 \mathrm{~g} / \mathrm{dl}$. All blood products were irradiated (20 Gy).

\section{Statistical analysis}

Analysis was based on disease status on September 30, 2000. Overall survival was measured from the beginning of HDCY to the date of death or last follow-up. Progression-free survival was determined for all patients and was calculated from the beginning of HDCY to the date of relapse, progression, toxic death or last follow-up. Disease-free survival only applies to patients who achieved complete remission using the proposed sequential treatment. Duration was calculated from the time of a complete remission assessment to the date of relapse, death or last follow-up confirming diseasefree patient status. Actuarial curves were estimated according to the Kaplan-Meier method and compared by the log-rank test (20). The analyses were performed using the SPSS software, version 7.5 for Windows 95.

\section{Results}

\section{Peripheral blood progenitor cell collection and toxicity}

Two patients (6.1\%) died during the aplastic phase following HDCY. One patient died of cardiac toxicity and one of sepsis. Thirtyone patients underwent leukapheresis on median day +13 (range 11-18). A median of 3.0 leukaphereses (range 1-8) were per- 
formed. The median number of mononuclear cells harvested was $1.40 \times 10^{8} / \mathrm{kg}$ (range 0.28-13.2), the median number of $\mathrm{CD} 34^{+}$ cells was $6.19 \times 10^{6} / \mathrm{kg}$ (range 1.07-29.3). Nineteen of 31 patients $(61.2 \%)$ required platelet and/or erythrocyte concentrate transfusions during the aplastic phase of CY treatment. All patients experienced nausea and vomiting (grade 1-3). Two patients (6.1\%) presented fever of unknown origin. One patient $(3.0 \%)$ showed a transitory skin rush and one patient (3.0\%) transitory liver toxicity (grade 2).

\section{Autografting and toxicity}

PBPC autografting was performed in 30 patients and one patient was transplanted using PBPC plus bone marrow. Complete hematological reconstitution occurred in 30 patients. One patient remained thrombocytopenic with platelet counts of less than $50 \mathrm{x}$ $10^{9} / 1$ three months after autografting, without bleeding. The median was 11 days (7-26) for granulocyte engraftment (neutrophil count $\left.>0.5 \times 10^{9} / 1\right)$ and 17 days (8-62) for platelet engraftment (platelet count $\left.>20 \times 10^{9} / 1\right)$. The median duration of hospitalization was 15 days (4-43). No patients remained transfusion-dependent on red blood cells or platelets following the procedure and all of them presented a stable engraftment. All patients experienced nausea and vomiting, and 30\% had diarrhea (grade 2-3). Grade 2-3 mucositis was observed in all patients. Most of the patients required antibiotic therapy and transfusion during the aplastic phase. One patient presented transient grade 1-2 hepatic toxicity. Two patients died in complete remission: one of cardiac failure 7 days after autografting and one of sepsis 10 days after autografting. Five patients died during disease progression after autologous transplantation. The autografting-related mortality was $6.4 \%$ ( 2 patients). Overall sequence-related mortality (HDCY plus transplant) was $12 \%$ (4 patients).

\section{Response and survival}

All patients were available for response after HDCY. Two patients died following HDCY. Ultimately, 19 of 33 (57.6\%) patients achieved complete remission before autografting. Distribution of complete remission according to status at HDCY is reported in Table 2. Most of the patients achieving complete remission were chemosensitive. Thirty-one patients underwent autografting. In addition, 6 of $33(18.2 \%)$ patients obtained complete remission. According to "intention to treat", $24(72.7 \%)$ achieved complete remission. Six patients did not achieve complete remission after completion of the procedure, one patient is alive on therapy and five patients died because of progression of disease in a median time of 6 months (3-14). One patient relapsed after complete remission for 12 months and is alive on therapy. Up to now, 24 patients have survived for a median of 400 days (40-1233) after the procedure. Twenty-three patients are in complete remission for a median of 373 days (35-1224) after autografting.

The overall survival was $70 \%$ for 33 analyzed patients (Figure 1A). The overall survival was $62 \%$ for NHL and $76 \%$ for Hodgkin's disease (Figure 1B). The diseasefree survival was $87 \%$ for NHL and $85 \%$ for Hodgkin's disease (Figure 1C). The progression-free survival was $62 \%$ for NHL and $50 \%$ for Hodgkin's disease (Figure 1D). No significant differences have been observed so far between NHL and Hodgkin's disease.

Table 2. Complete remission (CR) following high-dose cyclophosphamide (HDCY) and peripheral blood progenitor cell transplantation (PBPCT) according to status of disease.

\begin{tabular}{lcclc}
\hline Status & N & $\begin{array}{c}\text { After HDCY } \\
\text { CR (N, \%) }\end{array}$ & $\begin{array}{c}\text { After PBPCT } \\
\text { CR (N, \%) }\end{array}$ & $\begin{array}{c}\text { Final } \\
\text { CR (N, \%) }\end{array}$ \\
\hline Partial remission & 12 & $7(58.3)$ & $4(36.4)$ & $11 / 12(91.6)$ \\
Sensitive with relapse & 11 & $9(81.8)$ & $2(2.0)$ & $11 / 11(100)$ \\
Disease progression & 10 & $2(20.0)$ & 0 & $2 / 11(18.2)$ \\
Total & 33 & $19(57.6)$ & $6(18.2)$ & $24(72.7)$ \\
& & & &
\end{tabular}


Figure 1E shows that the overall survival at HDCY was $96 \%$ for chemosensitive patients and $15 \%$ for chemoresistant patients $(\mathrm{P}<0.0001)$. In addition, Figure $1 \mathrm{~F}$ shows that the overall survival at autografting was $92 \%$ for chemosensitive patients and $0 \%$ for still chemoresistant patients $(\mathrm{P}<0.0001)$.

\section{Discussion}

Intermediate- and high-grade NHL represent highly chemosensitive forms of malignancy. Even in patients who present advanced disease, the complete remission rate is higher than $50 \%$ using anthracycline-based
Figure 1. Estimated survival of patients treated with HDCY + HDVP16 ( \pm HDMTX) followed by PBPC transplant (Kaplan-M eier method). A, Overall survival. B, Overall survival after diagnosis (Hodgkin's disease (HD) and non-Hodgkin's lymphoma (NHL)). Not significant (log-rank test). C, Disease-free survival after diagnosis. Not significant (log-rank test). D, Progression-free survival after diagnosis. Not significant (log-rank test). E, Overall survival after high-dose cyclophosphamide (sensitive and resistant diseases). $* P<0.0001$ compared to sensitive diseases (log-rank test). F, Overall survival after autologous bone marrow transplantation (sensitive and resistant diseases). $* \mathrm{P}<0.0001$ compared to sensitive diseases (log-rank test).

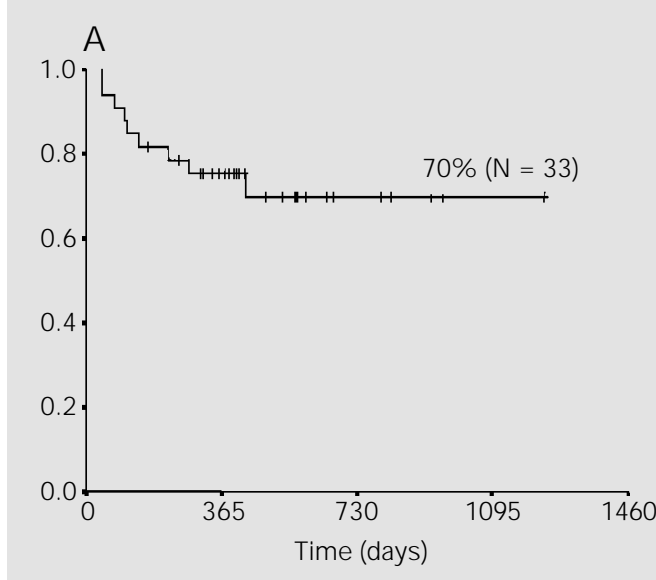

\section{B}

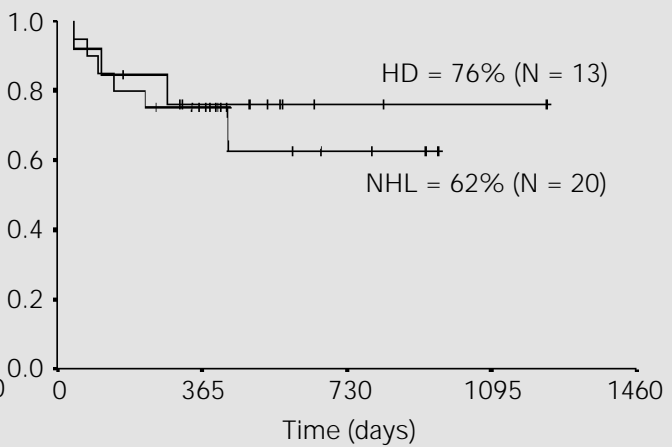

C
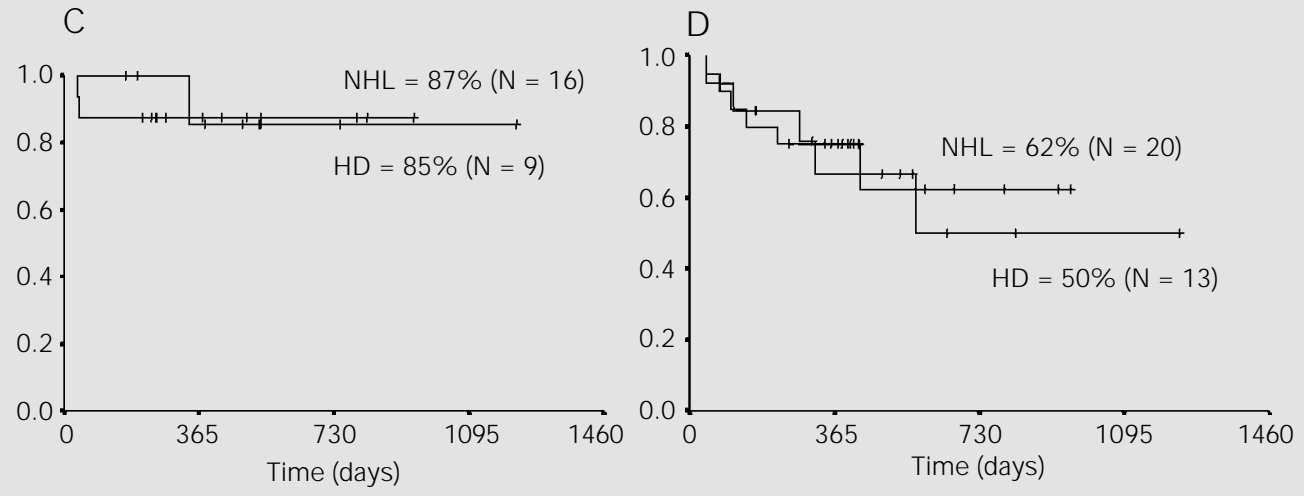

E

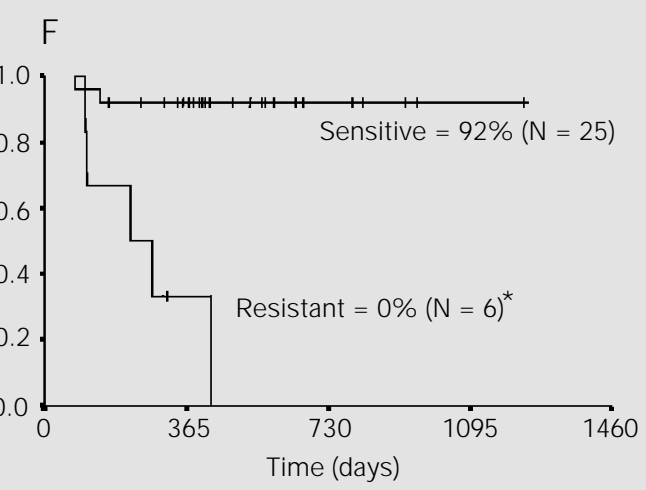


regimens (1-3). However, only $40 \%$ of patients can be cured. A substantial proportion of patients will relapse or fail to obtain complete remission with conventional chemotherapy $(21,22)$. Most patients need further treatment after front-line therapy (4-8). In Hodgkin's disease, 10 to $40 \%$ of patients who achieve complete remission after the initial treatment will relapse (10). The management of these refractory or relapsed Hodgkin's disease and NHL patients is usually disappointing and the long-term survival rate is less than $10 \%(9,10)$. Despite attempts at secondary "salvage" therapy, few patients can be expected to be cured of recurrent disease (20). Among the approaches to this clinical situation, HDT followed by ABMT or PBPC transplantation is useful in increasing survival and disease-free survival in these categories of patients (9-12). Several reports have indicated the advantages in terms of overall survival and disease-free survival of HDT plus autografting over conventional salvage therapy as salvage treatment (2225). The activity of HDCY at 7 or $4 \mathrm{~g} / \mathrm{m}^{2}$ in patients with NHL is well established. Cyclophosphamide was also efficient as a mobilization agent (26). The association of growth factors and HDCY accelerates hematopoietic recovery and significantly increases the yield of granulocyte colony-forming units and $\mathrm{CD} 34^{+}$cells (15). The number of collected PBPC is related to the intensity of previous chemotherapy lines (27). The use of CY at the dose of 7 or $4 \mathrm{~g} / \mathrm{m}^{2}$ plus growth factors permitted an effective PBPC collection in most of the pretreated patients with or without bone marrow involvement (28). In our single-center series of patients with resistant or relapsed intermediate/highgrade NHL or Hodgkin's disease treated with HDCY and HDT plus autografting, the overall complete remission rate was $72.7 \%$. Overall survival was $70 \%$. The rate of diseasefree survival was $87 \%$ for NHL and $85 \%$ for Hodgkin's disease. Progression-free survival was $62 \%$ for NHL and $50 \%$ for Hodgkin's disease. Our study did not show any significant differences between patients with NHL and Hodgkin's disease. These results compare favorably with data reported after conventional dose therapy and are comparable to the results achieved with the use of HDT and ABMT (21-25). Investigators from Stanford University (10) compared the results of transplantation for Hodgkin's disease patients after first relapse with data from historical controls. The four-year eventfree survival for relapsed patients with short initial remissions was estimated to be $56 \%$ following transplantation, compared with $19 \%$ for the historical controls $(\mathrm{P}<0.01)$. Overall survival rates were 58 and $38 \%$, respectively $(\mathrm{P}=0.15)$. In recurrent Hodgkin's disease, which is either primarily refractory or relapses earlier after conventional chemotherapy, protocols using ablative HDT followed by ABMT rescue can induce a complete remission in $50 \%$ of responders $(10,11)$.

In 1987, the combination of HDT and ABMT for relapsed NHL patients was considered promising (22). This large trial convincingly demonstrated the concept of sensitivity to conventional chemotherapy prior to transplantation as the most important variable related to results. In 1995, the multiinstitutional PARMA study compared conventional dexamethasone, cytarabine, and cisplatin chemotherapy with radiotherapy plus intensive chemotherapy followed by ABMT in 109 patients with chemotherapyresponsive first or second relapses of intermediate- or high-grade lymphomas. In this study, the response rate was significantly better in the ABMT arm (84 vs 44\%), and both five-year event-free survival (46 vs 12\%) and overall survival (53 vs 32\%) were significantly favorable in the transplantation arm (23). In our study, the procedure confirmed the impact of chemosensitivity of disease on the results, showing a rate of overall survival at the time of HDCY of $96 \%$ for chemosensitive patients and 15\% for 
chemoresistant patients $(\mathrm{P}<0.0001)$. The overall survival at the time of transplantation was $93 \%$ for chemosensitive patients and $0 \%$ for chemoresistant patients $(\mathrm{P}<0.0001)$. Mills et al. (18) reported a five-year progression-free survival of $49 \%$ for 55 chemosensitive patients with NHL, and $10 \%$ for 42 patients with chemoresistant lymphoma treated with HDT and ABMT. The main issue of this study is related to the important impact of HDCY on the diseases: $57.6 \%$ of patients achieved complete remission, 19 of 23 chemosensitive patients and 2 of 10 chemoresistant patients. This agrees with the fact that $\mathrm{CY}$ is a potent drug in the treatment of NHL (17) and justifies the dose escalation of this drug in the context of ABMT or PBPC autografting $(16,23)$. These results are favorable when compared with a complete remission ranging from 24 to $37 \%$ observed in refractory and relapsed aggressive NHL treated with conventional salvage treatments (4-6). Additionally, this could be explained by the high-dose intensity of drugs, like CY, VP-16 and methotrexate, used in the limit of toxicity and activity against the tumor. Moreover, most patients treated in this trial presented only one line of previous treatment. This is a very important point, i.e., high-dose sequential treatment followed by autografting should be used as soon as possible after relapse or persistent disease.

We were able to confirm that HDCY + VP-16 (plus methotrexate in Hodgkin's disease) followed by autologous PBPC proved to be effective and safe as salvage therapy in chemosensitive patients affected by aggressive NHL and Hodgkin's disease, showing acceptable and low mortality rates. HDCY also promoted efficient mobilization. However, truly chemoresistant patients did not benefit from this treatment regimen and should not be autotransplanted.

\section{Acknowledgments}

The authors acknowledge Arlete Rocha for secretarial assistance and Thelma Eloisa Felix de Oliveira for revising the English text.

\section{References}

1. Harris NL, J affe ES, Stein H, Banks PM, Chan J K, Cleary ML, Delsol G, De WolfPeeters C, Falini B \& Gatter KC (1994). A revised European American classification of lymphoid neoplasms: a proposal from the International Lymphoma Study Group. Blood, 84: 1361-1392.

2. Gottlieb J A, Gutterman J U, McFredie KB, Rodriguez V \& Frei 3rd E (1973). Chemotherapy of malignant lymphoma with adriamycin. Cancer Research, 33: 30243028.

3. McKelvey EM, Gottlieb J A, Wilson HE, Haut A, Talley RW, Stephens R, Lane M, Gamble J F, J ones SE, Grozea PN, Gutterman J, Coltman C \& Moon TE (1976). Hydroxyldaunomycin (adriamycin) combination chemotherapy in malignant lymphoma. Cancer, 38: 1484-1493.

4. Fisher RI, Gaynor ER, Dahlberg S, Oken MM, Grogan TM, Mize EM, Glick JH, Coltman J r CA \& Miller TP (1993). Comparison of a standard regimen (CHOP) with three intensive chemotherapy regimens for advanced non-Hodgkin's lym- phoma. New England J ournal of Medicine, 328: 1002-1006.

5. Gordon LI, Harrington D, Andersen J, Colgan J, Glick J, Neiman R, Mann R, Resnick GD, Barcos M, Gottlieb A \& O'Connell M (1992). Comparison of a second-generation combination chemotherapeutic regimen (m-BACOD) with a standard regimen (CHOP) for advanced diffuse non-Hodgkin's lymphoma. New England J ournal of Medicine, 327: 1342-1349.

6. Sertoli MR, Santini G, Chisesi T, Congiu AM, Rubagotti A, Contu A, Salvagno L, Coser $\mathrm{P}$, Porcellini A \& Vespignani $M$ (1994). Macop-B versus Promace-Mopp in the treatment of advanced diffuse nonHodgkin's lymphoma: results of a prospective randomized trial by the NonHodgkin's Lymphoma Cooperative Study Group. J ournal of Clinical Oncology, 12: 1366-1374.

7. Cabanillas F, Hagemeister FB, McLaughlin $P$, Velasquez WS, Riggs S, Fuller $L \&$ Smith T (1987). Results of MIME salvage regimen for recurrent or refractory lym- phoma. J ournal of Clinical Oncology, 5: 407-412.

8. Velasquez WS, Cabanillas F, Salvador $P$, McLaughlin $P$, Fridrik $M$, Tucker $S$, J agannath S, Hagemeister FB, Redman J R \& Swan F (1988). Effective salvage therapy for lymphoma with cisplatin in combination with high-dose Ara-C and dexamethasone (DHAP). Blood, 71: 117122.

9. Armitage J O (1998). Clinical results in peripheral blood autografting in lymphoma. In: Reiffers J \& Goldman J M (Editors), Blood Stem Transplantation. Martin Dunitz, London, UK, 101-127.

10. Horning SJ , Chao NJ , Negrin RS, Hoppe RT, Long GD, Hu WW, Wong RM, Brown BW \& Blume KG (1997). High-dose therapy and autologous hematopoietic progenitor cell transplantation for recurrent or refractory Hodgkin's disease: analysis of the Stanford University results and prognostic indices. Blood, 89: 801-813.

11. Yuen AR, Rosenberg SA, Hoppe RT, Halpern J D \& Horning SJ (1997). Compar- 
ison between conventional salvage therapy and high-dose therapy with autografting for recurrent or refractory Hodgkin's disease. Blood, 89: 814-822.

12. Hardingham J E, Kotasek D, Sage RE, Dobrovic A, Gooley T \& Dale BM (1993). M olecular detection of residual lymphoma cells in peripheral blood stem cell harvests and following autologous transplantation. Bone Marrow Transplantation, 11: 15-20.

13. Dreyfus F, Leblond V, Belander C, Gabarre J, Sutton L, Boccaccio C, Quarre MC, Ribrag V \& Goy A (1992). Peripheral blood stem cell collection and autografting in high risk lymphomas. Bone Marrow Transplantation, 10: 409-413.

14. Tarella $C$, Ferrero $D$, Bregni $M$, Siena $S$, Gallo E, Pileri A \& Gianni AM (1991). Peripheral blood expansion of early progenitor cells after high-dose cyclophosphamide and rhGM-CSF. European J ournal of Cancer, 27: 22-27.

15. Goldschmidt H, Hegenbart U, Haas R \& Hunstein W (1996). Mobilization of peripheral blood progenitor cells with highdose cyclophosphamide ( 4 or $7 \mathrm{~g} / \mathrm{m}^{2}$ ) and granulocyte colony-stimulating factor in patients with multiple myeloma. Bone Marrow Transplantation, 17: 691-697.

16. National Cancer Institute (1988). Sponsored study of classification of nonHodgkin's lymphoma: summary and description of a working formulation for clinical use. Cancer, 49: 2112-2135.

17. Wiernick PH, Canellos GP, Dutcher JP \& Kyle RA (1998). Neoplastic Diseases of the Blood. 3rd edn. Churchill-Livingstone, New York, NY, USA.

18. Mills W, Chopra R, McMillan A, Pearce R, Linch DC \& Goldstone AH (1995). BEAM chemotherapy and autologous bone marrow transplantation for patients with nonHodgkin's lymphoma. J ournal of Clinical Oncology, 13: 588-595.

19. Azevedo AM, Nucci $M$, Maiolino $A$, Vigorito AC, Simões BP, Aranha FJ , Tabak DG, Voltarelli J \& De Souza CA (2000). A randomized, multicenter study of G-CSF starting on day +1 or day +5 after autologous peripheral blood progenitor cell transplantation. Blood, 96: 383 (Abstract).

20. Kaplan EL \& Meier P (1958). Nonparametric estimation from incomplete observation. J oumal of the American Statistical Association, 53: 457-481.

21. Rosenberg AS (1987). Autologous bone marrow transplantation in non-Hodgkin's lymphoma. New England J ournal of Medicine, 316: 1541-1542 (Editorial).

22. Philip T, Armitage J O, Spitzer G, Chauvin F, Jagannath S, Cahn JY, Colombat P, Goldstone AH, Gorin NC, Flesh M, Laporte JP, Maraninchi D, Pico J, Bosly A, Anderson C, Schots R, Biron P, Cabanillas F \& Dicke K (1987). High-dose therapy and autologous bone marrow transplantation after failure of conventional chemotherapy in adults with intermediate-highgrade non-Hodgkin's lymphoma. New England J ournal of Medicine, 316: 14931497.

23. Philip T, Guglielmi C, Hagenbeek A, Somers R, Lelie HVD, Bron D, Sonneveld $P$, Gisselbrecht C, Cahn J Y, Harousseau $\mathrm{J}$ L, Coiffier B, Biron $\mathrm{P}, \mathrm{M}$ andelli $\mathrm{F}$ \& Chauvin $F$ (1995). Autologous bone marrow transplantation as compared with salvage chemotherapy in relapses of chemotherapy-sensitive non-Hodgkin's lymphoma. New England J ournal of Medicine, 333: 1540-1545.
24. Haioun C, Lepage E, Gisselbrecht C, Bastion Y, Coiffier B, Brice P, Bosly A, Dupriez B, Nouvel C, Tilly $\mathrm{H}$, Lederlin P, Biron P, Briere J, Gaulard P \& Reyes F (1997). Benefit of autologous bone marrow transplantation over sequential chemotherapy in poor-risk aggressive non-Hodgkin's lymphoma: Updated results of the prospective study LNH87-2. J ournal of Clinical Oncology, 15: 1131-1137.

25. Blay J Y, Gomez F, Sebban C, Bachelot T, Biron P, Guglielmi C, Hagenbeek A, Somers R, Chauvin F \& Philip T (1998). The international prognostic index correlates to survival in patients with aggressive lymphoma in relapse: analysis of the PARMA trial. Blood, 92: 3562-3568.

26. Kotasek D, Shepherd KM, Sage RE, Dale BM, Norman J E, Charles P, Gregg A, Pillow $A \&$ Bolton A (1992). Factors affecting blood stem cell collections following highdose cyclophosphamide mobilization in lymphoma, myeloma and solid tumors. Bone Marrow Transplantation, 9: 11-17.

27. To LB, Haylock DN, Simmons PJ \& J uttner CA (1997). The biology and clinical uses of blood stem cells. Blood, 89: 2233-2258.

28. Santini G, De Souza CA, Congiu AM, Nat $S$, Marino G, Soracco M, Sertoli MR, Rubagotti A, Spriano $M$, Vassallo $F$, Rossi $E$, Vimercati $R$, Piaggio $G$, Figari $O$, Benvenuto F, Abate $M$, Truini M, Ravetti J L, Ribizzi I \& Damasio E (1999). Highdose cyclophosphamide followed by autografting can improve the outcome of relapsed or resistant non-Hodgkin's lymphomas with involved or hypoplastic bone marrow. Leukemia and Lymphoma, 33: 321-330. 